\title{
Jurisprudência na cobrança de honorários profissionais em odontologia nos estados de São Paulo e Minas Gerais
}

\author{
Jurisprudence in collection actions in Dentistry from the States of \\ Sao Paulo and Minas Gerais
}

\author{
Márcia Vieira da Motta1, Daniel Romero Muñoz¹, Julio Cesar Fontana-Rosa1, Monica \\ Vieira da Motta Piacsek², Moacyr da Silva ${ }^{3}$, Fernando Jorge De Paula ${ }^{1}$
}

\begin{abstract}
Motta MV, Muñoz DR, Fontana-Rosa JC, Piacsek MVM, Silva M, De Paula FJ. Jurisprudência na cobrança de honorários profissionais em odontologia nos estados de São Paulo e Minas Gerais. Saúde, Ética \& Justiça. 2011;00(2):72-85.

RESUMO: A cobrança em odontologia tem sofrido alterações ao longo dos anos, e hoje coexistem diversos tipos de contraprestação para a atividade laborativa, como salários, proventos, soldos, gratificações e honorários. Os autores fizeram levantamento das jurisprudências de cobrança de honorários envolvendo cirurgiões dentistas nos tribunais de São Paulo e Minas Gerais, via Internet, e avaliaram os principais aspectos considerados pelo órgão julgador na decisão da lide. As jurisprudências abrangeram, em sua maioria, casos de reabilitação oral, implantes e ortodontia. A documentação odontológica mostrou-se fundamental para a proposição das ações pelos profissionais, sendo que a falta de indicação de participação do paciente nos registros imprimiram fragilidade na alegação do profissional em juízo. O tempo para prescrição das ações desta natureza sofreu alteração com a vigência do novo Código Civil, sendo hoje de 5 anos. Ainda foi observado o entendimento da reabilitação protética como uma atividade com finalidade estética e não reabilitadora funcional, limitada por fatores biológicos. Falhas básicas como a celebração de contratos com menores e falta de orientação quanto a orçamentos multidisciplinares também foram encontradas.
\end{abstract}

DESCRITORES: Odontologia/legislação e jurisprudência; Odontologia legal; Crédito e cobrança de paciente

\footnotetext{
1. Faculdade de Medicina da Universidade de São Paulo - FMUSP.

2. Faculdade de Direito, FMU, SP.

3. Faculdade de Odontologia da UNISANTA, SP.

Endereço para correspondência: Márcia Vieira da Mota. Departamento de Medicina Legal, Ética Médica e Medicina Social e do Trabalho da Faculdade de Medicina da Universidade de São Paulo - Av. Dr. Arnaldo, 455, Cerqueira César, São Paulo, SP. 01246-903. E-mail: depaulafj@yahoo.com.br
} 


\section{INTRODUÇÃO}

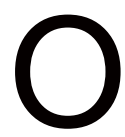
dicionário online Aulete define honorários como vencimentos pagos a profissionais liberais por serviços prestados ${ }^{1}$. O termo tem origem latina, honorartus, que significa conferir honra e dar crédito a alguém².

Dentre as formas de remuneração reconhecidas pela Organização Internacional do Trabalho (OIT), encontram-se aquelas relativas ao resultado do trabalho e aquelas relativas ao tempo despendido na realização do trabalho ${ }^{3}$. No caso da odontologia, a função mais comum seria a do cirurgião dentista (CD) com atividade em consultório e a forma de remuneração mais freqüente, o pagamento por trabalho realizado ou recebimento de honorários profissionais, como é usualmente reconhecido. Na prática, o profissional estabelece hoje diversas formas de prestação de serviço para com a sociedade, com diferentes tipos de remuneração. Docentes, por exemplo, costumam ser assalariados e peritos ou assistentes técnicos, prestadores de serviços.

Graça Leite, em 1962, ensinou que o conceito de remuneração estabeleceu-se na antiga Roma $^{4}$. Nessa época, os romanos perceberam que alguns serviços traziam diferenciação em sua execução e, conseqüentemente, deveriam guardar esta relação na forma de sua retribuição. Assim, por exemplo, as tarefas manuais permitiam uma avaliação exata, ou seja, a fixação do preço justo; enquanto que aquelas que requeriam sabedoria para a sua execução eram de difícil estimativa, uma vez que, via de regra, exigiam dedicação e sacrifício, revestindo-se, pois, de certo sentido de favor, o que inviabiliza uma fixação precisa de remuneração. Julgaram, então, que tais atividades, deveriam corresponder a uma remuneração sui generis que, além de cobrir as despesas do profissional, fosse uma prova de reconhecimento do favor empenhado em sua prestação, surgindo a idéia de honorários para dignificar esses préstimos ${ }^{4}$.

Percebe-se, nesta época, a dualidade entre o exercício profissional como arte ou ofício, como virtude ou profissão. Se ofício, mereceria pagamento, se arte, gratificação (honorarium). Platão, na República, já discute a dicotomia entre o exercício profissional da medicina: na verdade seria seu fim econômico ou social? Mais de um milênio depois, o conceito de honorários evoluiu, embora este sentimento um tanto incômodo de valoração econômica e afetiva do pagamento ao profissional da área da saúde continue. Este conflito ainda existe, muito embora o conceito de honorários tenha evoluído frente às novas condições econômicosociais. Graça Leite refere que, em meados do século passado, quando alguém era indagado quanto à sua percepção sobre a integralidade do pagamento referente a um tratamento (de saúde), respondia que a sensação de débito não se findava com o pagamento, como quando do pagamento do feitio de uma roupa ${ }^{4}$

Todavia, pondera-se que a sociedade vive hoje um momento de dessacralização social que ecoa na relação médico/paciente (e aqui se entende também $\mathrm{CD} /$ paciente), imprimindo-lhe impessoalidade e descontentamento à atividade profissional' ${ }^{5}$. Zimmermann et al. ${ }^{6}$ "apontam que atualmente os pacientes não se sentem mais devedores das reverências que caracterizavam os relacionamentos do passado em resposta ao próprio comportamento dos profissionais".

Alguns termos que se referem à contraprestação recebida pelo profissional em razão da realização de um tratamento em favor do paciente, de uso cotidiano por parte da população podem gerar imprecisões por interpretações errôneas de seus significados. É oportuno estabelecer diferenças e usos mais adequados para os termos equivalentes, uma vez que as respectivas responsabilidades profissionais e a base de cálculo relacionada a cada uma diferem conforme sua natureza, tendo tratamento diverso no âmbito do Direito Privado e Público ${ }^{7}$.

Em excelente artigo da Unicamp disponível para os alunos da graduação, resta definido que, de acordo com o tipo de atividade laborativa, podem-se distinguir distintos tipos de contraprestação. O SALÁRIO corresponde à remuneração, normalmente, em dinheiro, devida pelo empregador, em face do serviço do empregado, mais especificamente ao operário. De acordo com a natureza da sua destinação, este recebe uma complementação na denominação. Assim, existem, entre outros, os salários: mínimo, profissional, base, referência e família. O VENCIMENTO, também denominado PROVENTO, corresponde à remuneração recebida pelos funcionários públicos. Assim, uma pessoa que exerce um emprego público, regulamentado pelas leis do funcionalismo público, recebe o que normalmente se denomina vencimentos ou provento. O SOLDO corresponde à parte básica, fixa, da remuneração a que faz jus o militar conforme o seu posto ou graduação. Ao soldo acrescenta-se uma parte variável, a GRATIFICAÇÃO, dependente do tempo de serviço pela função que exerce. O lucro é a denominação empregada, normalmente, para significar a vantagem obtida pelos comerciantes. Assim, um 
indivíduo proprietário de uma casa comercial vende suas mercadorias e, uma vez abatidas as despesas, obterá uma vantagem denominada lucro. Finalmente, fala-se em HONORÁRIOS, quando se refere a uma espécie de contraprestação recebida pelos profissionais que exercem profissão liberal. Assim, o CD, o médico, o advogado, o engenheiro e outros que executam um trabalho para o seu cliente, têm sua remuneração denominada comumente de honorários ${ }^{8}$.

\section{REVISTA DA LITERATURA}

\section{Honorários como forma de contraprestação do tratamento odontológico}

$A$ realidade mostra que, na grande maioria dos casos, a convenção estabelecida entre o CD e a prática clínica está baseada em regras de direito privado, tal como uma locação de serviços, consoante com o disposto no antigo Código Civil brasileiro $^{9}$ de 1.916 em seus Artigos $1.216 \mathrm{e}$ seguintes, tendo sua nomenclatura transformada em prestação de serviços pelo novo estatuto civil ${ }^{6,10}$.

O contrato de prestação de serviços odontológicos estabelecido entre o profissional e o paciente, além de expressar, inequivocamente, direitos e obrigações para ambas as partes, deve seguir regras de cunho consumerista na forma da Lei no 8.078/906,11.

O novo Código Civil brasileiro (CCB) estabeleceu, em seu art. 594, que toda espécie de serviço ou trabalho lícito pode ser acordado mediante retribuição ${ }^{10}$. Já o Código do Consumidor, não obriga que as prestações de serviços sejam contratadas por escrito, sendo válido o trabalho realizado mediante acordo verbal ${ }^{11}$. Assim, a adoção de contrato pelo CD é facultativa, embora devesse ser prática ordinária a realização de uma competente documentação odontológica. Todavia, quando o contrato é adotado, deverá conter cláusulas válidas, pois estas constituem norma jurídica que vinculam as partes e deverão ser cumpridas por elas sob pena de execução patrimonial.

Dentre os princípios que regem esses contratos de prestação de serviço estão o da Autonomia, do Consentimento, da Obrigatoriedade e da Boa Fé12,13. No primeiro, os indivíduos são livres para estabelecer e estipular livremente, mediante acordo de vontades, a disciplina de seu interesse. No segundo, é imprescindível que as partes envolvidas em um contrato consintam o seu conteúdo, expressando suas vontades isentas de dolo, coação, fraude, ou qualquer outro vício. A declaração de vontade pode ser verbal, escrita, simbólica, direta ou indireta, expressa ou tácita ou, ainda, presumida. No terceiro, faz referência ao consentir, ou seja, as partes concordam em cumprir o acordo estabelecido. E o último, estabelecido no art. 422 do $C C B$, indica que a boa fé deve permear todos os contratos. Embora tenha um contexto subjetivo, traz como objeto a retidão no cumprimento mútuo da relação jurídica, considerando determinados padrões sociais estabelecidos e conhecidos.

Enfatiza-se que, de acordo com o art. 113 do $\mathrm{CCB}^{10}$, os negócios jurídicos devem ser interpretados conforme a boa-fé e os usos do lugar na sua celebração. Todavia, para ser válido, o contrato necessita obedecer aos requisitos do art. 104 do $\mathrm{CCB}^{10}$ : envolver agentes capazes, objetos lícitos e forma prescrita ou não de defesa em lei (Quadro 1).

Quadro 1. Requisitos legais para validade de contrato de prestação de serviços

\section{Agente Capaz e Legítimo}

As pessoas envolvidas na relação jurídica devem ser capazes de realizar o que acordam bem como devem constituir parte legítima, ou idônea, para efetivar a relação (Art. 3으, $4^{\circ}$ e $5^{\circ} \mathrm{CCB}$ ).

\section{Idoneidade do Objeto}

O serviço contratado deve manter identidade com a finalidade do contrato, ser lícito e possível.

\section{Forma Prescrita em Lei}

Refere-se à forma do documento que deve estar de acordo ou não aos requisitos impostos na legislação (se existirem).
Ex. A celebração de contrato tendo como uma das partes, menor de idade sem representação de seu responsável ou mesmo por pessoa física ou jurídica sem autoridade para celebrá-lo pode ser considerada nula ou anulável (ilegítimo).

Ex. O Contrato de prestação de serviços deve englobar procedimentos que são cientificamente reconhecidos pela ciência odontológica.

A licitude de um contrato não se determina pela sua natureza escrita ou verbal, mas, sim, pela determinação legal. Inexiste qualquer norma que obrigue o CD a ter um contrato por escrito com seu paciente. 
Zimmerman et al. ${ }^{6}$ discutem extensamente a validade dos contratos frente ao Código de Defesa do Consumidor. Quando válidos, entendem que os contratos são inatingíveis, a menos que ambas as partes os rescindam voluntariamente ou haja a escusa, por caso fortuito ou força maior.

Lembram que o art. 46, da Lei 8.078/90, dispõe que "os contratos que regulam as relações de consumo não obrigarão os consumidores se não Ihes for dada a oportunidade de tomar conhecimento prévio de seu conteúdo, ou se os respectivos instrumentos forem redigidos de modo a dificultar a compreensão de seu sentido e alcance" e que, no art. 47 do mesmo diploma legal, está previsto que "as cláusulas contratuais serão interpretadas de maneira mais favorável ao consumidor"10,6.

Já o art. 51 da lei consumerista prevê várias situações em que são nulas de pleno direito as cláusulas contratuais relativas ao fornecimento de produtos e serviços. Exemplificando algumas destas previsões legais consideraram: atenuar a responsabilidade do fornecedor dos serviços (CD) pelos vícios que apresentem; estabelecer obrigações consideradas iníquas, abusivas, que coloquem o consumidor (paciente) em desvantagem exagerada, ou seja, incompatíveis com a boa-fé ou a equidade; permitir ao fornecedor a variação do preço ajustado de forma unilateral, entre outras ${ }^{6,11}$.

Os autores apreciaram, ainda, os contratos frente aos seguintes artigos do Código Civil10: "Art. 597. A retribuição pagar-se-á depois de prestado o serviço, se, por convenção, ou costume, não houver de ser adiantada, ou paga em prestações."

Em se tratando de serviços de longa duração, como reabilitação oral ou ortodontia, a não consignação da forma de pagamento previamente ao início do tratamento pode implicar o entendimento de que a remuneração seria devida apenas após a sua conclusão, como sugere a norma vigente ${ }^{6}$. Embora seja de bom alvitre que o acordo quanto à remuneração seja estabelecido sempre previamente à prestação do serviço, é particularmente significativo nestes casos em que o tempo compõe uma variável importante na composição dos valores a serem considerados.

Nos dois artigos abaixo citados, entenderam que o legislador estabeleceu a importância dos prazos na prestação de serviços, evidenciando a importância do registro das ocorrências que pudessem prolongar o tempo para a conclusão do tratamento.

"Art. 598. A prestação de serviço não se poderá convencionar por mais de quatro anos, embora o contrato tenha por causa o pagamento de dívida de quem o presta, ou se destine à execução de certa e determinada obra. Neste caso, decorridos quatro anos, dar-se-á por findo o contrato, ainda que não concluída a obra."

"Art. 600. Não se conta no prazo do contrato o tempo em que o prestador de serviço, por culpa sua, deixou de servir."

Por outro lado, quanto aos prazos de prescrição, o CCB estabeleceu no §5ํㅡㄹ inciso II, art. 206, regra geral para os profissionais liberais, o que abarca as relações contratuais CD/paciente. Segundo a nova regra, prescreve em cinco anos a pretensão dos profissionais liberais em geral $\left.\right|^{6,10}$.

Finalmente, refletiram que, embora seja previsível a contratação verbal, fato corrente com a maioria dos cirurgiões-dentistas, é necessário criar condições para que toda a categoria se conscientize de que seu trabalho merece ser valorizado, não se prestando a submissão a contratos sem o mínimo de formalidade que garantam ao menos a prova da existência da relação jurídica ${ }^{6}$.

\section{Critérios para a fixação de honorários}

Alguns juízos podem ser considerados pelo profissional com o objetivo de fixar seus honorários. São estes os critérios: econômicos, gerenciais, deontológicos e legais.

\section{Critérios Econômicos}

O direito de fixar honorários não é ilimitado. Existe necessariamente o referencial de mercado que restringe os valores de acordo com o poder econômico da sociedade em que se exerce a profissão. Compreende, contudo, critérios subjetivos e objetivos na sua composição. Inicialmente deve cobrir a verba alimentar, que seriam os valores necessários para permitir remuneração que permita ao profissional viver em condições dignas. Os custos dos procedimentos, envolvendo os materiais, recursos humanos, logística, e os custos indiretos reais como aluguel, impostos entre outros, devem ser calculados usualmente por alguma unidade de trabalho (procedimento em si ou tempo despendido).

Entre os custos subjetivos, muitas vezes criticados, encontram-se prestígio profissional, qualificação, reputação, experiência, dificuldade inerente ao caso, valor da demanda, etc. Embora os custos de materiais eventualmente possam ser os mesmos, para um profissional experiente, os riscos inerentes ao procedimento são menores bem como o tempo despendido na resolução do caso. A valoração é subjetiva para o consumidor, mas objetiva para o profissional. Há custos em se 
manter atualizado, há custos atrelados à experiência em termos de responsabilidade profissional, entre outros.

\section{Critérios gerenciais}

\section{Oliveira e Oliveira Jr. ${ }^{14}$ destacaram que}

\begin{abstract}
"os honorários são responsáveis pela receita bruta do consultório, similarmente ao que ocorre com as demais empresas. Entretanto, boa parte dos profissionais encara a receita que entra no consultório como salário, gastando-a sem critérios, não levando em conta que administram a pequena empresa que é seu consultório particular, que possuem gastos fixos, gastos variáveis, sem falar na necessidade de reinvestimentos constantes no empreendimento e uma dedicação ao trabalho que vai muito além das horas que passam no atendimento dos pacientes".
\end{abstract}

Existem planilhas que podem auxiliar os profissionais a calcular seus custos fixos e variáveis mensais, de acordo com fórmulas matemáticas relativamente simples ${ }^{6}$. De fato, o cálculo dos custos fixos e variáveis é imprescindível para que qualquer profissional possa se auto-gerenciar como pessoa física ou jurídica.

$\mathrm{Na}$ Odontologia brasileira comumente se observa as formas de pagamento (a) por resultado, (b) por unidade de procedimento executado, (c) pelo valor global do tratamento ou, ainda, (d) pelo diagnóstico ou, menos freqüentemente, (e) pela capitação de pacientes. Na primeira situação, o custo norteia fortemente os valores dos honorários. Por outro lado, quando se opta pela cobrança baseada no valor global do tratamento, além do custo, que pode ser alto como em ortodontia, o total cobrado deve englobar o esforço do profissional ao longo do tratamento, bem como os riscos inerentes a qualquer atividade que gera expectativas pelo resultado. $O$ pagamento por capitação baseia seu valor na quantidade de pacientes atendidos, no pressuposto que com o maior número de atendimentos, os custos tendem a diminuir. Seria aquele em que o profissional recebe, de terceiros, o valor correspondente aos atendimentos unitários realizados em um período de tempo pré-determinado (por exemplo, um mês).

O pagamento por tempo está se tornando cada vez mais freqüente na Odontologia, e referese àquele em que o profissional recebe pagamento baseado no número de horas em que presta atendimento, não entrando, neste cálculo de salário, o valor do custo relativo aos atendimentos ou o número de casos atendidos.

Se, por um lado, a remuneração por honorários pode trazer a super valorização do tratamento, o atendimento por capitação pode trazer o subtratamento para 0 aumento da margem de recebimento do profissional. O salário, embora garanta certa estabilidade econômica ao profissional, também carrega em si um lado perverso já que não proporciona estímulo financeiro para maximizar o número de atendimentos. No Brasil, em 2010, Morita, Haddad e Araújo encontraram aproximadamente $27 \%$ dos profissionais registrados no CFO, com vínculo público, em estudo baseado no número de profissionais cadastrados no Sistema de Cadastro Nacional de Estabelecimentos de Saúde $(\mathrm{SCNES})^{15}$. De acordo com o Sindicato Nacional de Odontologia de Grupo (SINOG), cerca de $65 \%$ dos CDs brasileiros estão vinculados às operadoras de planos odontológicos ${ }^{16}$. Na rede credenciada, os dentistas podem ser remunerados por meio da tabela de valor de procedimentos especifica da operadora, via salário fixo por período de trabalho ou via grupo de procedimentos.

Os custos dos profissionais autônomos como dos credenciados pagos por unidade de trabalho compõem o valor da remuneração a ser recebida, embora para os primeiros, os honorários são estabelecidos em função de seus custos reais e lucro esperado, enquanto para os credenciados, existe o teto estabelecido pelas tabelas na rede credenciadora, e o mínimo estabelecido na tabela de Valores Referenciais para Convênios e Credenciamentos (VRCC), desenvolvida pela Comissão Nacional de Convênios e Credenciamentos ${ }^{17}$. Em qualquer das situações, o profissional deve saber o valor dos seus custos para estabelecer o seu valor de honorários, abaixo do qual estaria pagando para trabalhar.

\section{Critérios deontológicos}

O Código de Ética Odontológica estabelece os princípios que norteiam os deveres éticoprofissionais do $C D$, destacando-se os princípios da lealdade, honestidade, probidade, diligência, publicidade e independência. $\mathrm{Na}$ fixação de honorários, preconizaque devam serconsiderados ${ }^{18}$ : I - a condição sócio-econômica do paciente e da comunidade; II - o conceito profissional; III - o costume do lugar; IV - a complexidade do caso; V - o tempo utilizado no atendimento; VI - o caráter de permanência temporariedade ou eventualidade do trabalho; VII - a circunstância em que tenha sido prestado o tratamento; VIII - a colaboração do paciente durante o tratamento; IX - o custo 
operacional.

Alguns dos critérios acima não suscitam dúvidas, como a incorporação dos custos operacionais ou da valorização da competência do profissional na composição dos honorários, porém outros parecem ser conflitantes com as normas vigentes. Em que se pese o princípio da equidade na interpretação da isonomia frente à Constituição Brasileira, onerar o valor dos honorários considerando a condição socioeconômica do paciente constitui conduta não acolhida dentro dos preceitos morais e costumes nacionais. Mesmo que se encontre justificativa para a admissão de redução de valores quando na tratativa dos menos favorecidos, o exagero da cobrança em situações antagônicas não se justifica, uma vez que os cálculos de custos devam ser estabelecidos por meio de critérios justos e reais.

O entendimento do legislador com relação à fixação de honorários por costume do local merece atenção especial do profissional. Não se restringe aqui à noção de que os valores devem guardar apenas proporcionalidade com os valores cobrados na comunidade, já que o próprio mercado se encarrega de eliminar desvios. Como costume, considera-se também a natureza do processo remuneratório que, em uma lide, será matéria de avaliação pelo magistrado na arbitragem de honorários. Neste sentido, formas e desdobramentos quanto ao pagamento devem ser acordados com clareza, como pagamento em parcelas, pagamento por unidade de serviço concluído, estabelecimento de prazos, uso de tabelas, etc.

Apesar da autonomia do profissional em fixar seus honorários, se este for trabalhar em uma clínica que tem como costume a cobrança de valores tabelados, por exemplo, deverá documentar o entendimento dos pacientes que the forem encaminhados com relação à forma de pagamento exigida, por ser esta distinta do restante da clínica.

Com relação ao tempo despendido em um tratamento, não resta dúvida quanto à maior valorização de unidades de trabalho que são extensas ou difíceis. A ambiguidade encontrase justamente na imprecisão de planejamento inerente à área da saúde. O Código de Ética, neste caso, legitima a possibilidade de haver ajustes dos honorários, quando o caso exigir dedicação por períodos maiores do que o esperado ou quando o tempo for abreviado. Certamente a boa-fé deve pautar estas alterações bem como os preceitos legais e morais.

As circunstâncias em que tenha sido prestado o tratamento referem-se a fatores não inclusos ordinariamente nos valores dos honorários, porém que a eles podem ser acrescidos, como taxa de urgência, deslocamento, adicional noturno, entre outros. São custos operacionais não previstos rotineiramente, mas que, por onerarem o profissional liberal, podem ser repassados aos pacientes.

Considerando os princípios da boa-fé e justiça, concebe-se que o legislador, ao ponderar a colaboração do paciente no tratamento como fator partícipe da composição do honorário, entendeu que custos mais elevados se desprenderiam de tratamentos mais longos e fadados a re-feitura de trabalhos. Embora justo, nem sempre é fácil estabelecer em uma previsão de custos inicial este tipo de critério já que o comportamento humano não pode ser avaliado em apenas alguns contatos como geralmente ocorre em consultas de diagnóstico. De fato, o Código do Consumidor estabelece que um orçamento deva ser entregue ao consumidor contendo, a priori, o tempo previsto de execução do serviço. Tais considerações dizem respeito à regra adotada pelo Código, que é a Teoria Objetiva. Entretanto, o código abre exceção para a responsabilidade dos profissionais liberais com a apuração da culpa, Teoria Subjetiva, sendo que, para aqueles, não podemos aplicar o termo orçamento, e, sim, utilizar a expressão previsão de custos, uma vez que seus procedimentos podem exigir refeituras ou prolongamento do tratamento por razões inerentes à patologia ou conduta do próprio paciente.

\section{Critérios legais para fixação dos honorários}

Como a fixação de honorários ocorre ordinariamente por contrato entre particulares escritos ou verbais, os critérios são estabelecidos entre as partes e, na grande maioria das vezes, não é motivo de contestação. A lide costuma ocorrer quando o paciente torna-se devedor ou quando, não satisfeito com o serviço prestado (ou não prestado), questiona seu valor.

A cobrança do valor devido pode ser feita por notificação extrajudicial, por procedimento sumário, ação monitória ou por meio de ação de cobrança com rito ordinário, de acordo com a documentação existente e a vontade do executante. Nestes casos, o valor realizado no contrato será pleiteado e, em não existindo um, o valor pleiteado será relativo aos serviços que forem passíveis de comprovação frente à documentação existente segundo a interpretação em juízo de acordo com o Código Civil Brasileiro ${ }^{10} \mathrm{e}$ o Código do Consumidor ${ }^{11}$. Prescreve este direito, de acordo com o CCB, em 5 anos, contado o prazo a partir da conclusão dos serviços, cessação dos respectivos contratos ou mandatos ${ }^{10}$. 
A contestação do paciente com relação aos honorários é meritória quando este paga por serviços que não recebeu ou quando recebe serviços de qualidade inferior a acordada, entre outras situações. Nestas lides, usualmente cabe ao profissional comprovar o que foi acordado entre as partes e o que foi realizado. Em não havendo documentação, caberá ao magistrado avaliar se há ou não honorários devidos frente à avaliação pericial das provas fornecidas.

\section{OBJETIVOS}

O presente estudo teve por objetivo realizar levantamento, com conseqüente análise qualitativa, das ações empreendidas por cirurgiões-dentistas e pacientes, referentes a cobranças de honorários, no Tribunal de Justiça do Estado de São Paulo (TJSP) e de Minas Gerais, por meio da Internet, com o intuito de analisar os principais aspectos envolvidos nestas ações e que foram considerados pelo órgão julgador ao longo dos anos.

\section{METODOLOGIA}

O levantamento foi realizado por meio da análise documental de delineamento longitudinal, utilizando a Internet com a finalidade de recuperar as ações de cobrança de honorários promovidas por cirurgiões-dentistas em desfavor de seus pacientes nos Tribunais de Justiça do Estado de São Paulo e de Minas Gerais. Para a análise dos principais aspectos discutidos e que foram considerados pelos desembargadores, utilizou-se a metodologia qualitativa.

Para o acesso à Internet foi utilizado o programa Mozilla Firefox, e para o processamento dos documentos encontrados, editoração dos textos e realização das planilhas de cálculos foi utilizada a suite Libreoffice. Para a concretização do levantamento, foi acessado o campo de consulta alusivo às jurisprudências do Tribunal de Justiça do Estado de São Paulo e Minas Gerais nos endereços eletrônicos:

\section{$\checkmark$ https://esaj.tjsp.jus.br/cjsg/consultaCompleta.do \\ $\checkmark$ http://www.tjmg.jus.br/juridico/ea/ \\ formEspelhoAcordao.do}

Os unitermos pesquisados foram "ação + cobrança + dentista". A seleção de documentos utilizou como critério de exclusão, aqueles que expressamente não tinham a conotação de cobrança de honorários por tratamento. Após a seleção dessas ações, empreendeu-se o acesso ao inteiro teor dos acórdãos, pesquisando-se os aspectos discutidos e considerados pelo órgão julgador. O tratamento estatístico dos resultados obtidos foi pautado na análise descritiva dos dados apresentados.

\section{RESULTADOS}

Foram encontradas, no total, 23 jurisprudências que correspondiam à matéria pesquisada, sendo 15 acórdãos de São Paulo e 8 de Minas Gerais.

Em um destes casos, o paciente acordou tratamento para colocação de implante e foi surpreendido com uma cobrança quanto aos honorários do serviço de prótese que desconhecia. $\mathrm{O}$ próprio protesista reconheceu que não foi acordado o preço da parte reabilitadora do tratamento, pois "quem quer receber o melhor não pergunta quanto custa, ele quer o melhor"19. Em outros dois casos, os pacientes alegavam desconhecer o orçamento (de endodontia e clínica) $)^{19,20}$ e se recusavam a pagar, enquanto em outro processo, o paciente sustou cheque alegando que se tratava de cheque caução e não pagamento pelo serviço prestado ${ }^{21}$.

A não existência de contrato foi motivo de contestação em ação em que o paciente reconhecia que deveria pagar pelo tratamento recebido, porém, verbalmente o teto acordado para o tratamento havia sido de seis mil reais, de modo que se recusou a pagar o excedente sobre este valor. Neste caso, não houve nem ao menos avaliação quanto aos custos realizados no tratamento ou se o excedente era justo ou não. Ficou estabelecido que o devido fosse apenas o valor acordado verbalmente ${ }^{22}$.

A qualidade do serviço prestado em um caso de periodontia foi motivo de lide em que o paciente abandonou o tratamento ao final e se recusava a pagá-lo, já que iria concluí-lo com outro profissional que o acolheu no pós-operatório cirúrgico e the serviu de testemunha quanto à qualidade (na verdade, falta de) do serviço previamente prestado (declarou, a profissional, que a cirurgia da gengiva "não foi bem feita"). Restou estabelecido no exame pericial que o serviço fora de fato prestado ao paciente e que a qualidade não comprometia a saúde do mesmo ou seu tratamento, de modo que os honorários eram devidos ${ }^{23}$.

É interessante que esta postura quase que delatora profissional também foi observada em processo envolvendo instituição de ensino. Em ação movida por paciente de curso prático de implantes oferecido por equipe de professores prestadora de serviços para a instituição, esta apontou que, de fato, a responsabilidade seria da empresa do professor responsável pelo curso, se escusando 
da responsabilidade solidária que teria no caso. O magistrado repudiou esta conduta e também o fato de a defesa declarar que o pagamento devido era apenas do custo do material, e não da mão-de-obra. Entretanto, neste caso, a perícia não comprovou o dano ou as alegações da paciente ${ }^{24}$.

Cobrança indevida foi observada em caso em que o paciente havia pago o início do tratamento ortodôntico e continuou a ser cobrado pela clínica, mesmo tendo o profissional declinado o caso após avaliação dos exames/ diagnósticos ${ }^{25}$. Em situação semelhante, a cobrança ocorreu após o paciente ter desistido do tratamento, posteriormente à fase de diagnóstico, ao ser informado que o tratamento seria de cinco anos ao invés de dois ${ }^{26}$.

A licitude da cobrança de honorários foi avaliada em litígio em que o profissional celebrou contrato de ortodontia e reabilitação oral com paciente menor de idade. No tocante a anulabilidade do contrato, entendeu o magistrado que "a apelante não pode se beneficiar do erro para o qual contribuiu", uma vez que no contrato não havia qualquer campo específico que permitisse a conclusão que a paciente seria menor de idade. Não poderia então se esquivar das obrigações assumidas a partir do ato de contratação, demonstrando má-fé no intuito de se livrar de todo o custo da obrigação conscientemente assumida ${ }^{27}$.

Em uma situação peculiar de cobrança de honorários, uma cirurgiã-dentista foi condenada a pagar danos morais à paciente por ter realizado a cobrança mediante escândalo e intimidação na porta do paciente devedor ${ }^{28}$. Em outra, o profissional se recusou a pagar a verba pericial (por ausência de disponibilidade financeira) e, em não existindo prova precisa do tipo de serviços prestados ou valores determinados, foi considerada improcedente a ação de cobrança de honorários ${ }^{29}$. A não realização de prova pericial para comprovar imperícia que justificasse ressarcimento foi destacada em acórdão em que o paciente não requereu a realização da prova pericial nos autos, tendo sustentado suas alegações apenas nas afirmações do profissional que o assistiu após abandonar o tratamento em lide. Neste caso, concluiu o magistrado:

"Os serviços profissionais somente podem
ser considerados inadequados se assim
forem constatados por prova técnica. O mero
desconforto do réu e o abandono do tratamento
em sua fase final não constituem prova suficiente
à assertiva de que houve erro capaz de justificar
o não pagamento de honorários devidos à
autora"23.

A perícia foi fundamental em três acórdãos. No primeiro, comprovou frente à documentação existente a legitimidade da cobrança de honorários ${ }^{30}$. No segundo, que os trabalhos propostos no plano de tratamento não haviam sido realizados de modo que não deveriam ser cobrados (embora houvesse comprovação da existência de provisórios, o que sugere que tanto o preparo quanto a realização dos provisórios não se encontravam no orçamento) ${ }^{31}$. Por fim, no último, a perícia indicou diversas falhas técnicas básicas em um caso em que, em primeira instância, considerou a sentença que o ônus do insucesso do tratamento deveria ser atribuído ao paciente, que optara por um tratamento menos recomendável, porém com baixo custo. Na decisão jurisprudencial, considerou o magistrado que a profissional32: "Ofereceu tratamento alternativo e estabeleceu preço pelo serviço. Logo, não pode se eximir da responsabilidade assumida por não ter conseguido realizar com sucesso o tratamento por ela mesma indicado'32.

Os demais acórdãos recuperados tratavam de assuntos diversos, como competência do tribunal ou cobrança de honorários devidos por empresas a cirurgiões-dentistas, à exceção de um, em que o profissional foi dispensado de apresentar as fichas cadastrais e orçamentárias de todos os seus clientes da época em que ser tratava a lide, tendo em vista que o paciente (que contestava o pagamento dos honorários) já havia anuído os valores por meio da assinatura da confissão de dívida. Avaliou o relator, neste caso, que se presume aceito o orçamento e os valores fornecidos pelo profissional ${ }^{33}$.

\section{DISCUSSÃO}

O novo Código Civil Brasileiro (2002) estabelece em seu art. 594 que toda espécie de serviço ou trabalho lícito pode ser acordado mediante retribuição ${ }^{10}$. Por seu turno esse Código, assim como o Código de Defesa do Consumidor, não obrigam que as prestações de serviços sejam contratadas por escrito, sendo válido o trabalho realizado mediante acordo verbal ${ }^{10,11}$.

Portanto, quando se faz referência a contrato de prestação de serviços odontológicos, é comum subentender o contrato expresso, esclarecendo que este engloba tanto o verbal como o escrito ${ }^{34}$. Em princípio, o nosso direito despreza os formalismos inúteis, deixando ao alvedrio das partes a escolha da modalidade convinhável para a emissão de vontade ${ }^{35}$. De Paula et al. ${ }^{36}$, esclareceram que "por lei não existe nenhuma imposição da adoção de contrato escrito na prestação de serviços odontológicos no que diz respeito à forma da manifestação de vontade. Comumente é realizado de forma verbal. Invariável é a imperativa realização da documentação odontológica”. 
O contrato de prestação de serviços odontológicos escrito pode se revestir de um formalismo inútil, principalmente, quando simplesmente repete artigos já previstos em lei ou, pior, quando faze constar, em seu corpo, cláusulas abusivas. De Paula et al. ${ }^{36}$ ponderaram que "poucas cláusulas contratuais favorecerem o dentista em um processo. Isso é mais do que evidente. O mérito do debate está em derredor do próprio tratamento; do ato profissional e suas conseqüências. Dos cuidados adotados no pré, trans e pós-operatórios e não em um contrato de adesão".

Em ação de cobrança de honorários profissionais, a 27ํㅡㄹ Câmara de Direito Privado do TJSP estabeleceu que "impende lembrar que na exegese dos contratos deve-se ter em vista a real intenção manifestada pelas partes quando de sua celebração". Tanto assim que os contratos verbais têm o mesmo amparo legal que os escritos, consoante lição de Orlando Gomes, que "não é o instrumento que lhe dá existência, mas o encontro de duas declarações convergentes de vontades, emitidas no propósito de constituir, regular e extinguir, entre os declarantes, uma relação jurídica patrimonial de conveniência mútua"37.

Nos processos de cobrança, para demonstrar essa convergência de vontades, existem vários tipos de provas admitidas em Direito que podem ser produzidas em um processo, desde que não sejam obtidas de maneira ilícita. Os meios de prova são ilustrativamente citados no Código de Processo Civilis, são eles: o depoimento pessoal (art. 342 a 347), que consiste em uma arguição da parte pelo juiz, determinado de ofício ou a pedido da parte contrária, ressalvam-se o sigilo de certas profissões, como a odontológica, e a imputação de culpa sobre o próprio depoente; a confissão (art. 348 a 354), que é a admissão em juízo da verdade de um fato que beneficia a parte em contrário; a exibição de documento ou coisa (art. 355 a 363), que exige ordem judicial emanada por juiz para que a parte exiba documento ou coisa sob sua guarda $^{10,34,35,37}$.

Os tipos de prova considerados são: Documental (art. 364 a 399) - todos os documentos que compõem o corpo probatório do processo, os quais devem acompanhar a inicial ou a contestação, podendo ser juntados aos autos depois de decorridos os prazos desses, somente quando se tratar de fato novo relativo à causa (fato já existente, cuja prova foi conseguida posteriormente); Testemunhal (art. 400 a 419) - consiste na apresentação de testemunhas para serem ouvidas em juízo (no prazo de até dez dias antes da audiência), para fim de complementação de prova anteriormente produzida, ou a ser produzida em audiência; Pericial (art. 420 a 439) - provas produzidas por meio de exame, vistoria ou avaliação efetivada por perito técnico, que pode ser acompanhado por assistentes nomeados pelas partes; Inspeção Judicial (art. 440 a 443) - ato pelo qual o juiz, de ofício ou a requerimento da parte, pode, em qualquer fase do processo, inspecionar pessoas ou coisas, a fim de se esclarecer fato que interesse à decisão da causa ${ }^{10,34,35,37}$.

É por entre os meios de prova que as partes demonstram a existência dos fatos controvertidos que integram o litígio, e de que o juiz tira dados e elementos para formar sua convicção ${ }^{39}$.

Esses tipos de prova tiveram fundamental importância no desfecho favorável à cobrança empreendida por um CD, em que o paciente foi condenado ao pagamento dos honorários devidos. Durante o processo, a paciente alegava que jamais havia estado no consultório daquele dentista e que a prova oral - testemunha - não podia ser considerada idônea com o fim de prejudicá-la. No mérito do acórdão, os desembargadores entenderam que os elementos dos autos, em relação à paciente, eram totalmente desfavoráveis: o perito apontou a realização de serviços registrados na ficha clínica da paciente e a prova oral sustentava o pedido inaugural, quer em relação à presença da ré no consultório do autor para que se submetesse aos tratamentos devidos em seus dentes, quer quanto aos serviços prestados, inclusive os de prótese dentária. A esse processo corresponde a seguinte jurisprudência, que foi editada em razão do tópico ora abordado:

EMENTA: Honorários de profissional liberal. Cobrança. Dentista. Serviços odontológicos prestados. Ação julgada procedente. Alegação de prescrição. Inocorrência. Não fluência da prescrição e que ocorre em cinco anos. Demonstração da realização dos serviços odontológicos prestados pelo autor. Perícia e com base nas anotações da ficha da paciente. Prova oral que dá pleno respaldo à pretensão inaugural. Recurso desprovido. Não há ultrapassagem do prazo prescricional, não se aplicando a regra do Código Civil de 1916. O novo Código Civil não repetiu a regra anterior do artigo $178, \S 6^{\circ}$, IX do estatuto revogado, e o seu advento alterou o prazo prescricional, não se aplicando a regra do artigo 2.028 por não ocorrer redução. Na verdade, o prazo restou dilatado pela regra do artigo $206, \S 5^{\circ}$, inciso XX do atual Código, estabelecendo cinco anos por se cuidar de pretensão dos profissionais liberais em geral, procuradores judiciais, curadores e professores pelos seus honorários, contado o prazo da conclusão dos serviços, da cessação 
dos respectivos contratos ou mandato. Restou demonstrado através da perícia a realização dos serviços odontológicos prestados pelo autor e a prova oral dá pleno respaldo à pretensão inaugural, quer em relação à presença da ré no consultório do autor para se submeter aos tratamentos devidos, quer quanto a alguns serviços prestados ${ }^{30}$.

Por essa ementa, observa-se que entre as alegações preliminares encontra-se a prescrição do direito de pleitear em juízo a cobrança dos honorários em virtude de haver transcorrido o prazo de um ano, com fundamento no art. 178, IX, $\S 6^{\circ}$, do Código Civil de 1916 (já revogado) ${ }^{9}$.

Com a vigência do Novo Código Civil, o assunto merece novas incursões, pois, do mesmo modo que o código anterior, este não faz alusão à categoria dos dentistas. De fato, o Título IV - Da Prescrição e da Decadência - em seu art. 206, § 5, estipula para os profissionais liberais, de modo geral, o prazo prescricional de cinco anos contados da data da conclusão dos serviços prestados ${ }^{10}$. Como o código vigente não faz alusão particularmente ao CD, mas também não o distingue de outros profissionais liberais, subentende-se que o prazo prescricional atual, para prescrição da cobrança de seus honorários, foi estendido para cinco anos.

Para a ciência odontológica resta claro que o tratamento reabilitador por meio de próteses visa prioritariamente à recuperação das funções mastigatória e fonética, e não tem exclusivamente fins estéticos, tendo em vista que é uma situação recoberta de incertezas pelos limites biológicos inerentes a cada caso. Porém, ainda existe o entendimento por muitos magistrados de que os tratamentos protéticos são procedimentos de fim (obrigação de resultados), gerando sérias conseqüências, inclusive contrariamente ao texto legal, no modo que a responsabilidade civil do cirurgião-dentista é verificada, inclusive em relação ao ônus probante. De acordo com o inciso I do art. 333 do CPC, cabe ao autor, que em uma ação de cobrança é o CD, o ônus de provar os fatos constitutivos de seu direito. Quem alega deve provar a existência do fato. Já o inciso II do mesmo art. 333, incumbe ao réu, paciente, demonstrar a existência de fato impeditivo, modificativo ou extintivo do direito do autor. É também importante ressaltar a regra contida no CDC que prevê a inversão do ônus em favor do consumidor, com o objetivo de facilitar a defesa ${ }^{11}$.

Emum dosacórdãos recuperados, ao cobrar judicialmente seu paciente, o CD (autor) alegou em sua inicial que prestou ao seu paciente serviços odontológicos, que consistiram nos seguintes procedimentos: a) cirurgia para afixação de dois implantes, comlevantamento doseiomaxilar, enxerto ósseo e membrana ( $\mathrm{R} \$ 2.400,00)$; b) colocação de três coroas provisórias ( $\mathrm{R} \$ 300,00)$; c) colocação de núcleo radicular em ouro no canino superior $(R \$$ $680,00)$; d) colocação de coroas provisórias sobre os implantes e conexões (R\$ 450,00); e) cirurgia plástica com deslize retalho na região do primeiro e segundo pré-molares superiores $(\mathrm{R} \$ 650,00)$; f) dois núcleos em ouro sobre os implantes (R\$1.200,00); que, terminada a prestação dos serviços, o paciente (réu) desapareceu, deixando um débito de $\mathrm{R} \$$ 10.440,66. Em sua defesa, o paciente sustentou, em suma, que realizou o tratamento odontológico; que o profissional lhe garantiu que o tratamento não passaria de $R \$ 6.000,00$; e que, desse valor, adiantou ao dentista o valor de $R \$ 4.600,00$. Os desembargadores entenderam que, embora incontroversos nos autos a prestação de serviços e o inadimplemento do contrato verbal, o mesmo não ocorreu em relação ao montante do débito total requerido, havendo o paciente reconhecido em sua defesa que o valor máximo do débito seria de $R \$$ $6.000,00$. Ponderaram que "não há um dever de provar, nem à parte contrária assiste o direito de exigir a prova do adversário. Há um simples ônus, de modo que o litigante assume o risco de perder a causa se não provar os fatos alegados e do qual depende a existência do direto subjetivo que pretende resguardar por meio da tutela jurisdicional. Isto porque, segundo máxima antiga, fato alegado e não provado é o mesmo que fato inexistente". Assim, não restou aos ilustres julgadores, opção a não ser deferir apenas o montante incontroverso - R\$ 6.000,00 -, admitido na contestação, e não comprovado o pagamento pelo paciente ${ }^{22}$.

\section{EMENTA: AÇÃO DE COBRANÇA. PRESTAÇÃO DE SERVIÇOS. VALOR - ÔNUS DA PROVA. Se o fato constitutivo do direito do autor, sobre o total do débito em discussão, não resta provado nos autos, o caso é de se deferir, tão somente, os valores reconhecidos pelo réu, tendo em vista o não atendimento da regra do art. $333, \mathrm{I}$, do $\mathrm{CPC}^{22}$.}

Nesse mesmo sentido, o acórdão abaixo indica que foi reconhecido o direito ao recebimento do CD, apenas em virtude da efetiva comprovação do tratamento realizado:

EMENTA: "PRESTAÇÃO DE SERVIÇOS ODONTOLÓGICOS. CREDEN-CIAMENTO DE PROFISSIONAL LIBERAL. CONTRATO ROMPIDO UNILATERALMENTE PELO CONTRATANTO. AÇÃO DE 


\begin{abstract}
COBRANÇA. SERVIÇOS PROFISSIONAIS COMPROVADAMENTE REALIZADOS. REMUNERAÇÃO DEVIDA. O profissional contratado, que viu rompido o contrato ajustado, fará jus à remuneração proporcional ao serviço realizado. APELAÇÃO. EXPRESSÃO INJURIOSA. PRETENSÃO PARA QUE SEJA RISCADA ADMISSIBILIDADE. EXEGESE DO ARTIGO 15, DO CÓDIGO DE PROCESSO CIVIL. O artigo 15 do Código de Processo Civil permite que o juiz mande riscar as expressões injuriosas lançadas pelo recorrente, não importando que haja, ou não, o animus injuriandi. AÇÃO JULGADA PROCEDENTE. RECURSO IMPROVIDO"40.
\end{abstract}

Por isso é de suma importância que o profissional tenha "amor aos papéis" 41 . Com uma documentação claudicante nada conseguirá provar em juízo. Ao revés, o profissional que se preocupar, durante sua atividade clínica, em tomar cuidados para perpetrar um competente prontuário poderá a qualquer momento confirmar a realização de determinado ato, a oportunidade correta de intervenção, a escolha do melhor tratamento, a anuência do paciente quando estiver envolvido procedimento de risco, etc. Nunca é demais solicitar a assinatura do paciente demonstrando a participação quando do andamento do tratamento, pois ficha clínica elaborada apenas pelo CD é vista com desconfiança pelos julgadores. Neste sentido, merece atenção a seguinte ação monitória:

AÇÃO MONITÓRIA. HONORÁRIOS
PROFISSIONAIS. DENTISTA. NECESSIDADE
DE COMEÇO DE PROVA ESCRITA. FICHA
CLÍNICA DE ACOMPANHAMENTO DO
PACIENTE. INSUFICIEENCIA. DESCABI-
MENTO. Ficha clínica elaborada por cirurgião
dentista não pode ser considerada prova
escrita, vez que não há elementos que
autorizem considerar o documento como prova
de tratamento dentário e de cobranças parciais,
porque não existem indícios de participação
do réu na sua elaboração, unilateralmente
apresentado pela autora.

Ainda hoje, como os resultados demonstraram, verifica-se que o número de ações de cobrança de honorários ainda é pequeno. $\mathrm{Na}$ existência de conflito, o mais civilizado é procurar a justiça para efetivar o ressarcimento pelo tratamento realizado e não pago. Para evitar aborrecimentos, o CD não deve procurar intentar nenhuma intimidação de paciente para o recebimento, tendo em vista o dano moral que pode ser gerado, como no caso descrito nos resultados onde a cirurgiã dentista fez escândalo na porta da devedora e acabou tendo que ressarcir pelos danos morais causados ${ }^{28}$.

Contam os autos que a profissional, para receber o complemento de seus honorários, dirigiu-se "à residência da cliente, ou responsável pela cliente, e, segundo o seu relato, do qual não destoaram as testemunhas ouvidas, suas vizinhas, fez escândalo, ameaças, buzinou, chamou a atenção dos moradores e ainda xingou. As testemunhas da autora mostraram-se seguras e firmes e acompanham até mesmo o relato da testemunha da ré que confirma a sua presença no local e sua iniciativa de cobrar pessoalmente a dívida - ou o que achava fosse seu crédito - não importa. A partir de então surge a versão conveniente, para se adequar aos fatos: a visita foi normal, a dentista. Assim, foi ofendida, buzinou sim, mas sem querer, foi o alarme de seu carro que acidentalmente disparou. Sua versão soa pueril, não convence, é simplesmente oportunística. A ré procurou, através da intimidação do escândalo constrangedor, receber o que desejava. Evidentemente não escolheu o método aconselhável, teria sido melhor que outro tipo de alarme tivesse antes soado em sua consciência".

Importa salientar que a consciência tranqüila de qualquer cidadão é o seu maior bem. Isso também é válido para todo CD. Portanto, atualmente, os profissionais atuantes devem se adaptar a essa nova realidade da prática odontológica cujo teor é não reduzir a atuação profissional em razão do medo de sofrer processos, pelo contrário, esse temor surge da falta de conhecimento - ou da insipiência das leis e suas influências no cotidiano da atuação profissional. Nesse sentido, é evidenciado que não é necessário ter conhecimento profundo da ciência do direito, mas, a partir do momento em que o CD tem noção de sua importância e de como se dá a aplicação das normas, Ihe é permitido desenvolver um raciocínio lógico fundamentado na legislação, na doutrina e na jurisprudência, analisando os casos que aconteceram antes do seu. Sem dúvida, esses são parâmetros para que qualquer cirurgião-dentista possa exercer a profissão de forma mais tranqüila, sem medos, com um desenvolvimento ético essencial $^{42} \mathrm{e}$, quando realizar um tratamento em um paciente inadimplente, cobrá-lo judicialmente.

\section{CONCLUSÃO}

De acordo com a literatura e com base nas ementas pesquisadas, conclui-se que:

1) As ações empreendidas centravam-se basicamente nas áreas de reabilitação oral com próteses e implantes e em casos de ortodontia; 
2) A documentação odontológica mostrouse fundamental para comprovar as alegações do profissional, revestindo-se como elemento de prova em juízo. Documentações com poucos registros e falta de indicação da participação do paciente expõem a fragilidade das alegações do profissional em juízo;

3) Coube aos profissionais, na maioria dos casos, o ônus de provar em juízo que os fatos que lhe foram imputados pelo paciente eram improcedentes;

4) Acordos verbais foram reconhecidos, porém necessitaram ser comprovados por outros meios (tais quais provas documental e testemunhal);

5) Todos os procedimentos relativos aos tratamentos devem ser listados e aprovados na previsão de custos, pois, em uma possível lide, fases usualmente compreendidas para a realização de procedimentos fins, como adequação de meio ou preparo de boca e de provisórios, terão seus custos questionados, já que não constavam na documentação inicial;
6) A não cobrança de honorários, como nos casos de clínicas-escola, não afasta a responsabilidade do profissional e das instituições sobre o caso;

7) Tratamentos que envolvem mais de um profissional ou serviços prestados por terceiros devem sempre ser esclarecidos aos pacientes que devem indicar formalmente este entendimento (ex. pagamento de protético, custos de restaurar dente cujo tratamento endodôntico foi realizado por outro profissional, fase protética e cirúrgica dos implantes, entre outros);

8) É importante a documentação quanto à temporalidade dos trabalhos provisórios quando da instalação dos mesmos, tendo em vista que, em uma possível lide, o exame pericial poderá ocorrer anos depois da instalação do trabalho, o que compromete sua integridade bem como do remanescente dentário;

9) De acordo com o novo Código Civil, prescreve em cinco anos o prazo para a propositura de ação de cobrança de honorários.

Motta MV, Muñoz DR, Fontana-Rosa JC, Piacsek MVM, Silva M, De Paula FJ. Jurisprudence in collection actions in Dentistry from the States of São Paulo and Minas Gerais. Saúde, Ética \& Justiça. 2011;00(2):72-85.

ABSTRACT: Payment in Dentistry has changed over the years and today diverse forms of compensation coexist such as salaries, fees and gratitude. The authors recovered all the collection actions filed in Sao Paulo and Minas Gerais, online, and evaluated the main considerations by the judging body when deciding the suits. Most jurisprudence was from cases of oral rehabilitation, implants and orthodontics. Correct dental documentation was proven fundamental in the professional's propositions, while failure to indicate the patient's active participation on the records turned the allegations fragile. The elapsed time for the action to be prescribed increased from the previous Civil Code to the new one (5 years). The basic understanding regarding prosthetic rehabilitation still is that of an esthetic nature and not of a functional one, limited by biological factors. Basic flaws such as celebrating contracts with minors and lack of patient orientation regarding payment for multidisciplinary treatments were also observed.

KEYWORDS: Dentistry/jurisprudence \& legislation; Forensic dentistry, Patient credit and collection.

\section{REFERÊNCIAS}

1. Aulete C. Dicionário Aulete. São Paulo; 2011 [citado 19 jun. 2011]. Disponível em: http://aulete.uol.com. br/site.php?mdl=aulete_digital.

2. Cunha AG. Dicionário etimológico da língua portuguesa. Rio de Janeiro: Lexikon; 2010.

3. Cherchiglia ML. Remuneração de trabalho médico. Um estudo dobre seus sistemas e formas em hospitais gerais de Belo Horizonte. Cad Saúde Publica. 1994;10(1):67-79.

4. Graça Leite V. Odontologia legal. Salvador: Editora
Era Nova; 1962.

5. Khouri PR. Erro médico. Rev Consulex. 1999;1(35):15-21. In: Pitta GBB, Castro AA, Burihan E. Angiologia e cirurgia vascular: guia ilustrado. Maceió: UNCISAL/ECMAL \& LAVA; 2003 [citado 5 jun. 2011]. Disponível em: http://www.lava.med.br/ livro/pdf/marcia_responsabilidade.PDF.

6. Zimmermann RD, De Paula FJ, Silva M. Honorários profissionais do cirurgião-dentista. In: Silva $M$, Zimmermann RD, De Paula FJ. Deontologia 
Motta MV et al. Jurisprudência na cobrança de honorários profissionais em odontologia nos estados de SP e MG.

odontológica: ética e legislação. São Paulo: Editora Santos; 2011.

7. Carneiro GB. Conheça a diferença entre salário, vencimento e remuneração. Belo Horizonte; 2008. Disponível em: http://www.ufmg.br/pfufmg/index. php/pagina-inicial/saiba-direito/109-conheca-adiferenca-entre-salario-vencimento-e-remuneracao

8. Daruge Jr E. Honorários profissionais do cirurgião dentista e suas implicações éticas e legais. 2008 [citado em 5 jun. 2011]. Disponível em: http:// www.fop.unicamp.br/dos/odonto_legal/downloads/ graduacao/honorarios__ profis_CD_aplicacoes_ eticas_legais2008.doc.

9. Brasil. Lei no 3.071 , de 1ำ de janeiro de 1916. Código civil [citado 5 jun. 2011]. Disponível em: http://www. planalto.gov.br/ccivil_03/leis/L3071.htm.

10. Brasil. Lei $\mathrm{n}^{\circ} \mathbf{1 0 . 4 0 6}$, de 10 de janeiro de 2002. Institui o código civil [citado 5 jul. 2011]. Disponível em: http://www.planalto.gov.br/ccivil_03/leis/2002/ L10406.htm\#art2045.

11. Brasil. Lei $n^{\circ} \mathbf{8} .078$, de 11 de setembro de 1990 . Dispõe sobre a proteção do consumidor e dá outras providências [citado 5 jul. 2011]. Disponível em: http://www.planalto.gov.br/ccivil_03/Leis/L8078. htm.

12. Hammerschimitt I. Aspectos éticos e legais do contrato de honorários advocatícios. Florianópolis: OAB/SC Editora; 2008.

13. Azevedo AJ. O principio da boa fé nos contratos. Rev CEJ. 1999;3(9) [citado 5 jul. 2011]. Disponível em: http://www2.cjf.jus.br/ojs2/index.php/cej/article/ view/237/399.

14. Oliveira RN, Oliveira Jr OB. Honorários profissionais: sua importância no contexto do consultório odontológico. Rev Odont Soc. 1999;1(1,2):51-4.

15. Morita MC, Haddad AE, Araujo ME. Perfil atual do cirurgião dentista brasileiro. Maringá: Dental Press Editora; 2010.

16. Sindicato Nacional das Empresas de Odontologia de Grupo (SINOG). Assistência suplementar à saúde no Brasil, segmento odontológico: panorama do segmento de odontologia. 2011 [citado 5 jul. 2011]. Disponível em: http://www.sinog.com.br/downloads/ panorama_planos_odontologicos_mar2011.pdf.

17. ComissãoNacionaldeConvênioseCredenciamentos. Valores referenciais para procedimentos odontológicos. 2010 [citado 4 jul. 2011]. Disponível em: http://www.apcd.com.br/vrpo.pdf.

18. Conselho Federal de Odontologia (CFO). Código de ética odontológica. 2009 [citado 4 jul. 2011]. Disponível em: http://cfo.org.br/wp-content/ uploads/2009/09/codigo_etica.pdf.

19. Brasil. Superior Tribunal de Justiça. Acórdão em declaração negativa de relação jurídica e inexistência de débito. São Paulo. MOR, OUG e CMY, e JCTS. Relator: Desembargador Windor Santos, 17 ago. 2010.

20. Brasil. Superior Tribunal de Justiça. Acórdão em Ação de cobrança honorários de profissional liberal. São Paulo. MRFR e IMF. Relator: Desembargador Eros Piceli, 14 set. 2009.

21. Brasil. Superior Tribunal de Justiça. Acórdão em ação de cobrança de honorários de cirurgião dentista. São Paulo. ASS e ETS. Relator: Desembargador Fernando Bráulio, 22 nov. 2001.

22. Brasil. Superior Tribunal de Justiça. Acórdão em Ação de Cobrança. Minas Gerais. VC e JVOH. Relator: Desembargador Guilherme Luciano Baeta Nunes, 9 nov. 2010.

23. Brasil. Superior Tribunal de Justiça. Acórdão em ação de cobrança. São Paulo. ARR e MS. Relator: Desembargador Ricardo Negrão, 19 out. 2010.

24. Brasil. Superior Tribunal de Justiça. Acórdão em prestação de serviços. Ação de Indenização. São Paulo. ASVC e APCD (Santo André) e Implantodent. Relator: Juiz Ruy Coppola, 27 maio 2010.

25. Brasil. Superior Tribunal de Justiça. Acórdão em dano moral. São Paulo. COIFE e MSG. Relator: Desembargador Antonio Marson, 28 mar. 2007.

26. Brasil. Superior Tribunal de Justiça. Acórdão em Ação de Cobrança. São Paulo. LICOS e AS. Relator: Desembargador Andrade Neto, 13 abr. 2011.

27. Brasil. Superior Tribunal de Justiça. Acórdão em ação de responsabilidade civil c.c. indenização por danos morais. São Paulo. ASS e CSS, e VCBM e Banco Itaú. Relator: Desembargador Hugo Cripaldi, 26 abr. 2011.

28. Brasil. Superior Tribunal de Justiça. Acórdão de cobrança de divida de honorários com o recurso de escândalo e intimidação na porta do devedor. São Paulo. AMBP e outro, e ANTF e outro. Relator: Desembargador Gilberto de Souza Moreira, 28 abr. 2010.

29. Brasil. Superior Tribunal de Justiça. Acórdão de Cobrança. Honorários de profissional liberal. São Paulo. JCVD e READ. Relator: Juiz Ruy Coppola, 29 jan. 2002.

30. Brasil. Superior Tribunal de Justiça. Acórdão em honorários de profissional liberal. Cobrança. São Paulo. AFSS e JGR. Relator: Desembargador Kioitsi Chicuta, 2 set. 2010.

31. Brasil. Superior Tribunal de Justiça. Acórdão em ação de cobrança. Minas Gerais. PMDD e CSC. Relator: Juiz Gouveia Rios, 1 jul. 2003.

32. Brasil. Superior Tribunal de Justiça. Acórdão em responsabilidade civil. São Paulo. CP e NG. Relator: Desembargador Luiz Ambra, 2 mar. 2011. 
33. Brasil. Superior Tribunal de Justiça. Acórdão em honorários profissional liberal (dentista). Ação de cobrança. São Paulo. KSC e RBGVM. Relator: Desembargador Antonio Benedito Ribeiro Pinto, 6 fev. 2007.

34. Monteiro WB. Direito das obrigações. In: Maluf CAD, Silva RBT. Curso de direito civil. 34. ed. São Paulo: Saraiva, 2003.

35. Pereira CMS. Responsabilidade civil. 9a ed. Rio de Janeiro: Forense; 1999.

36. De Paula FJ, Santos ML, Silva M. Processos judiciais: análise dos aspectos legais da responsabilidade civil do cirurgião-dentista em relação aos atendimentos dos tribunais. Rev Assoc Paul Cir Dent, Santos São Vicente. 2002;132:17-8.

37. Gomes O. Contratos. 26a ed. São Paulo: Forense Jurídica; 2007.

Recebido em 27/09/11

Aprovado em 26/10/11
38. Brasil. Lei no 5.869 , de 11 de janeiro de 1973. Institui o Código de Processo Civil [citado 5 jul. 2011]. Disponível em: http://www.planalto.gov.br/ccivil/leis/ L5069.htm.

39. Marques JF. Instituições de direito processual civil. Rio de Janeiro: Ed. Forense; 1959.

40. Brasil. Superior Tribunal de Justiça. Acórdão em prestação de serviços odontológicos. Credenciamento de profissional liberal. São Paulo. SEPA e CCSPAS, e LMT. Relator: Desembargador Emanuel Oliveira, 9 mar. 2010.

41. Silva M.; De Paula FJ. SOESP. Documentação para a odontologia segura [citado 4 jul. 2011]. Disponível em: http://www.soesp.org.br/documentacao/index. html.

42. Silva M, Zimmermann RD, De Paula FJ. Deontologia odontológica: ética e legislação. São Paulo: Ed. Santos; 2011. 